\title{
Journaling: A Cross-cultural Approach to Transcend Individual Limitations Among Learners
}

\author{
Kashi Raj Pandey* \\ Department of Languages and Mass Communication, Kathmandu University, Dhulikhel, \\ Nepal
}

\begin{abstract}
While writing and reading have certain specific uses in the broader aspect of life and cultural practices, this paper focuses on improving a researcher's practice as a teacher and learner in inclusiveness, multiplicity, multiculturalism, and possibility of various perspectives in any given contexts. Taking autoethnography as a methodological referent in writing narratives, that deals with my own and students' lived experiences about journaling and its impact on transformation, this research looks into the dialectical nature of knowing through reflection about self practices whilst taking the cultural context of teaching in multiple perspectives. Responding to a number of questions including how a habit of maintaining journal helps the practitioner in cherishing multicultural thoughts, this work is equally a room that tries to find answers to the research question-- When and how do the learners realize a need for cross-cultural understanding?

Along with participants' narratives and other related theories this paper also covers the researcher's encounter with Dr. Inspection, and a letter to the Subject Committee. In addition, an acrostic poem and a Haiku also give the picturesque of the ongoing discourse among teachers and students, teachers and management and management and students in any educational institutions being Mount Kailash University (MKU) ${ }^{1}$, a prototype.
\end{abstract}

Keywords: journaling, auto-ethnography, multiculturalism, reflective practice and transformation

\section{Introduction}

Journaling in its various forms is "a means for recording personal thoughts, daily experiences, and evolving insights" (Hiemstra, 2001, p. 20). Honoring the past in our own words with our own uncensored reflections, we document our memories before they are lost. The process often evokes conversations with self, another person, or even an imagined other person. The advantage available in most journaling formats of being able to review or reread earlier reflections and a progressive clarification of insights is possible. Journaling for this research is to analyze, reconsider and question 
experiences within a given context through individual and collective reflection. For example, students in the researcher's classroom have found that the realities of their practical experiences did not match with what they had already learned from theories in previous classes. With this proposition, I agree with Moon $(1999$, p. 4) that "the process of reflecting on the disparities between your expectations and actual experience enables you to become more engaged with the process of your learning." In this context, reflective practice has strong ground for the overall development of the practitioners to improve their writing from different points of view.

\section{Ontological, Epistemological and Axiological Considerations}

Hitchcock and Hughes (1989) state that "the basic ontological and epistemological assumptions held by any researcher will shape the kind of methodology which those researchers will adopt" (as cited in Hart, 2004, p. 15); and Denzin and Lincoln (2005) disclose that a set of ideas or framework is ontology (p. 21). Individual thinking and progress is shaped and judged by society, culture, and values. It is also the same in the process of transformation of students and teachers in this research. While people judge everything relatively according to time and space, there is nothing as universal or central truth. Agreeing on this, Luitel (2009) also reveals, "Aspects of my ontology are relativistic without which contextual meaning making turns out to be a difficult endeavor" (p. 31). When I see multiple people and socio-cultural events to weave from all around and in accordance with my ontological standpoint, the epistemology of my research is located largely within interpretivism, because "human experience is chaotic and messy, requiring a pluralism of discursive and interpretive methods that critically turn text back upon themselves in the constant emancipation of meanings" (Spry, 2001, p. 727) where I look at the world as a sensible critic. It also draws on critical theory and utilizes postmodern forms of textual representation thereby promoting the notion of epistemological pluralism when there are stories all around us.

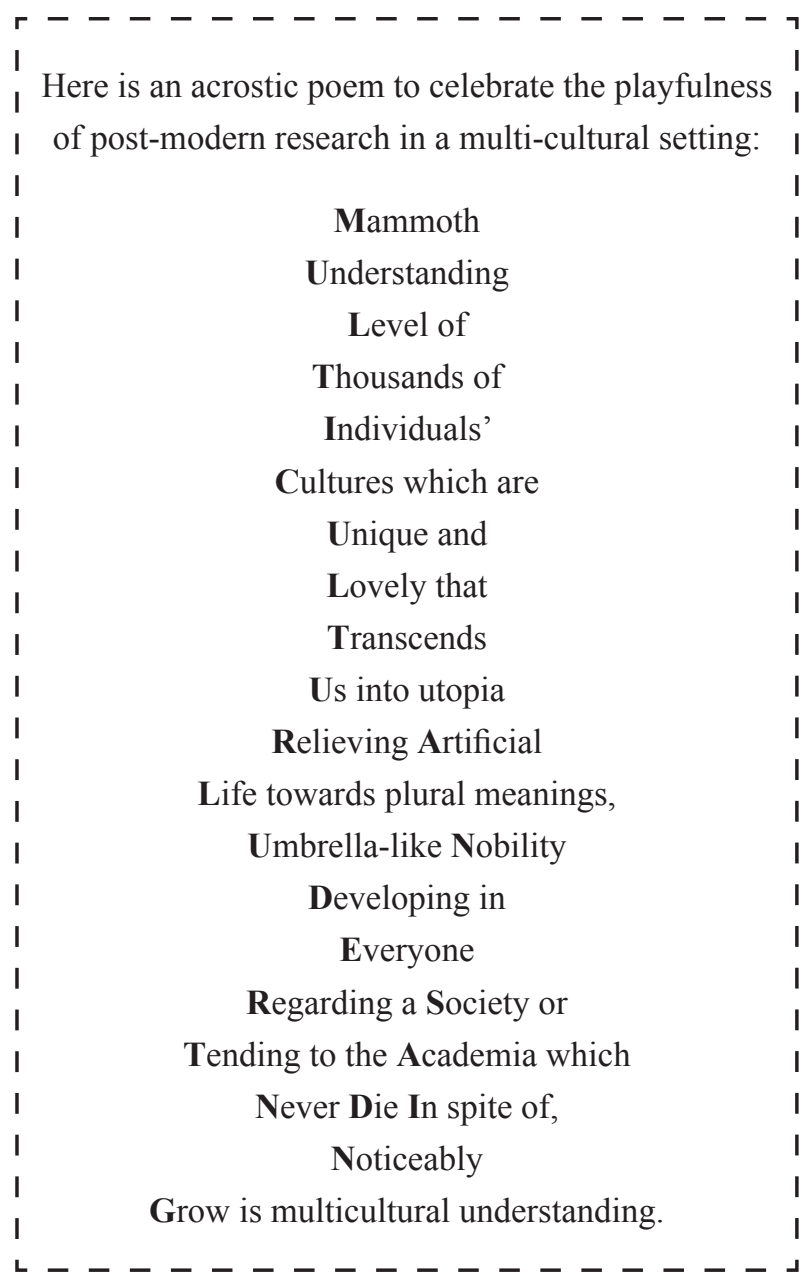


Working with transactional/subjectivist approach, I believe in "multiple ways of knowing" (Guba \& Lincoln, 2005). Luitel (2009) also argues that "an exclusive postmodern epistemology of knowing as ironic gazing is likely to over-celebrate the ironic aspect of language, thereby reducing knowledge to an exclusively subjective, fluid and fragmented form" (p. 173). This way, knowledge is not confined in deductive mode whereas it is generated from multiple subjects instead. In this journey of epistemological process that is guided by axiology, the study of the theory of values, where people are brought up in different settings according to their cultures could be the nectar of this work.

\section{Methodology}

A community of interpreters can work so actively where a context is open to interpretation and reflection with a willingness to engage in self appraisal. Among interpretivism, criticalism, and postmodernism paradigms, interpretivism has emerged in the social sciences to break out of the constraints imposed by positivism. Interpretivism as Taylor, Sattelmaier, and Luitel (2012) claim, "is concerned primarily with generating context-based understanding of people's thoughts, beliefs, values, and associated social actions". Taylor, Settelmaier, and Luitel (2012) share that "a new era" of "paradigmatic and methodological pluralism" (Paul \& Marfo, 2001) has been emerged to create necessary scholarly conditions for transformative research to flourish. With its emphasis on the relationship between socially-engendered concept formation and language, it could be referred to as the interpretive paradigm. I agree that "researcher's epistemological, ontological, and methodological premises may be termed a paradigm, or an interpretive framework, a basic set of beliefs that guides action (Guba, as cited in Denzin \& Lincoln, 2005, p. 22). Here, the interpretivist paradigm demands a set of feelings and beliefs that the researcher has about the world and how it should be understood and studied.

Interpretivism as it is characterized by a belief in a socially constructed, subjectively-based reality, one that is influenced by culture and history, "epistemologically, interpretivism gave rise to two key epistemic metaphors so as to guide my research journey: knowing as interpreting and constructing" (Luitel, Belbase, $\&$ Taylor, 2008, p. 31). The focus of my research also thrived the same way as it still retained the ideals of researcher's subjectivity and researcher as active collector and expert interpreter of data. In fact, change is inevitable and is affected by multiple realities expecting to transform for the betterment. So was the case in students' progress in writing with their reflective practices, because as an interpretivist researcher, when I prepare myself and "the students for the writing task by developing their interpretive skills" (Colonna \& Gilbert, 2006, p. v), I think that expressive and constructive factors are twin aspects of one reality. Making them (myself too) "read between the lines" I explored varied factors about students at MKU using journaling to improve their writing from different points of view.

While this paper revolves around multiparadigmatic approach, an overlap between and among different paradigms in the research, it is equally based on criticalism and postmodernism that search for concepts to shed light on and to help form 
a changing empirical world. Mirchandani (2005) says:

From postmodernism, seen as a combination of epistemological and empirical moments, we get the ability to continue living modern lives: making hypotheses, collecting data, and drawing conclusions, given backbone and confidence by sets of new conceptual tools and also a renewed modesty about the absoluteness of our findings or conclusions. We have always bracketed our shortcomings and our blind spots to get on with the business at hand. This combined postmodernism has given us the ability to recognize, acknowledge, and even thematize these shortcomings and still get on. (p. 110)

During my research too, the participants have become self critical while exploring the best of their (our) self reflections honoring the multiple ways of representation, every moment, coming up with the different thoughts, incorporating them in the context and documenting we could best assimilate according to our past interaction with the society, our nature, and culture/s in a wider arena.

Likewise, I agree with Denzin and Lincoln $(2005$, p. 7) that "the Qualitative Researcher as Bricoleur (proficient at performing a large number of diverse tasks ranging from interviewing to observing, to interpreting personal and historical documents, to intensive self-reflection and introspection) uses the tools of his/her methodological trade". Qualitative research, broadly defined, means "any kind of research that produces findings not arrived at by means of statistical procedures or other means of quantification" (Strauss \& Corbin, 1990, p. 17) and instead, the kind of research that produces findings arrived from real-world settings where the "phenomenon of interest unfolds naturally" (Patton, 2001, p. 39). As an interpretive researcher, I sought clarification, understanding, and extrapolation to similar situations of the status of reflective writings in my research participants.

\section{Postmodern Research Paradigm}

The postmodern condition, as an important change to society in the late twentieth century, has also influenced teaching learning. Postmodernism being the major paradigm of this research, the focus will be at the profound influence on the learning environment according to the needs of the learners in this complex and current postmodern society where they live. Leading to a democratic learning environment, I propose that learners get an opportunity to create an own personal narrative. Hence, this paper aims to cover the unique quality of possessing the potential of exploring multiple corners of participants cultivating in them the ability to think from social, spiritual, emotional, cultural or intellectual perspectives in finding a deeper meaning and understanding.

\section{Auto-ethnography as Method}

In the course of my students' journey of journaling, I thought auto-ethnography as the most suitable method because this makes the learning, the researcher, and the students realize who they are and how this process of journaling worked as catharsis in real life situations. Bolton (2001) captures how a writer is more comfortable as his writing works as a tool of purgation, "the writing has made me feel completely different 
about Simon's death; it has made me deal with it in a different way. I can now see how I wasn't responsible; though my mother still feels very guilty" (p. 19).

Here, the difference in feeling between the son and mother is all that one wrote and the other did not. In this case I do agree with Luitel, Belbase, and Taylor (2008) who also state that "Auto-ethnography opened my eyes to see who I am. Autoethnography opened my mind to realize who I am. Auto-ethnography opened my soul to understand what I am doing and what I need to do" ( $\mathrm{p}$. 94). My study, therefore, is more based on an inductive approach when the theory doesn't always fit the facts and for we need to revise our theory to better predict reality. This study is focused on individual journaling and observations embracing the tradition of further enquiry, identity and change according to the space and time including the necessity or possibility in me and in my participants.

After choosing the topic of my research, I thought of different methodologies to apply. However, auto-ethnography made me more comfortable than anything that was available, and suitable for my study. I followed auto-ethnography as methodology that also worked as a heuristic method, the process of discovering things for oneself and learning from one's past experiences.

This method offers the reader multiple places to stand in the story, multiple levels of emotionality and experience to which they can connect through their own experiences in the world. During this process, readers interact with the characters in the text, becoming ethnographers themselves and coming to their own conclusions about what it all means. (Angrosino, 1998, p. 41; Bochner, 1994, p. 31, as cited in Berger, 2001, p. 508). Self-culture dialectics, writing as inquiry, performative nature of language, and writing several texts in multiple genres were some of the strategies applied in my research.

I used auto-ethnography as aspects of methodology, method and genre of my inquiry. Auto ethnography, as Creswell (2002) claims is "a reflective self examination by an individual set within his or her cultural context" (p. 438). Believing this, I have leaped into this research while agreeing with Ellis and Bochner (2000) who also think "auto-ethnographical genre of writing and research displays multiple layers of consciousness, connecting the personal to the cultural" (p. 739) aspects.

As an "insider's methodology, I used auto-ethnography in which my personal and professional experiences became the key basis of this inquiry" (Luitel, 2009, p. 35). By nature, being a university teacher, I too always happen to read, write, and interact with students preparing them to produce an individual portfolio, a journal every semester.

I chose writing, a suitable activity, to encourage reflection because it, I believe, captures the original experience, would never get lost and could be available for others too to read and provide feedback. It also gives an "opportunity for the writer to reinforce and check her/his understanding” (Moon, 1999). Writing also promotes subjective 
objectivity, a way of distancing oneself from the initial experience and of distinguishing between the actual experience and its interpretations from within.

When qualitative approach is very broad, I preferred to use critical postmodernist theory that encompasses multiple perspectives, even questioning the self (here, the researcher) time and again. Postmodernism, as Taylor, Sattelmaier, and Luitel (2012) claim, "elicits both fear and favor via its basic principle: Be suspicious of all grand narratives." In this connection, Pereira (2007) further elaborates:

It accepts "only" the partiality of description, and it is "with" this limitation in mind that a multi- perspectival approach has value. It promises no solution, offering only a greater understanding of complexity through the development of a wider and deeper perspective; an understanding that assists the practicing researcher. (p. 202)

Auto-ethnography is "a genre of writing and research that connects the personal to the cultural, placing the self within a social context" (Reed-Danahay, 1997). She elaborates these texts as they are usually written in the first person and feature dialogue, emotion, and self-consciousness as the stories are affected by history, social structure, and culture. Whitehead (2000) says:

I want to start by claiming that you and I are similar in that you, like me, are conscious of asking yourself a question of the form, 'How do I improve what I am doing?' I also want to locate such questioning within the value-laden contexts of your practical activities in education. (p. 24)

Auto-ethnographic texts in my research too are narrative written accounts of important everyday life experiences as observed, understood, and communicated by and among the participants. Here, the individual, life in relation to the society plus context, and writing are so interdependent that this process feeds on one another to produce a more authentic and vivid accounts of interpretive and experimental reality. Auto-ethnographic research is conducted by interpreting personal documents, letters and recollections of important events in a person's life through the process of account making (Denzin \& Lincoln, 2000). Such research reflects what the researcher deems worthy of investigation, which is in turn shaped by her/his maturity level, general state of mind, and academic exposure.

\section{Writing as Inquiry}

I, as the teacher, also as the researcher stepped into the classroom once a week, divided students into groups, facilitated the class, and then students in turn discussed within the subject matter, with teacher's frequent moderation and facilitation, learning happened. According to the individual understanding, they all reflect the outcome through journal writing. This way, instead of one way, the learning took place in multiple levels.

Writing was traditionally viewed as the act of taking thoughts from the mind and putting them out in the world with the help of specific skills of composition and rhetorics. "Recent researches demonstrate that the process of telling and writing personal stories is a powerful means of fostering teachers' professional growth" (ElbazLuwisch, 2002, p. 403). The postmodern conception of language, however, tells us that 
it is "not the result of one's individuality; rather, language constructs the individual's subjectivity in ways that are historically and locally specific" (Richardson, 2005). Journaling has various benefits as it comes through and from within the self-reflection on what has already taken place and is happening in one's life experiences.

In keeping with my epistemological standpoint, I adopted a multi-method approach to address my research questions, also subscribing to methodological pluralism. Adopting the stance of researcher as bricoleur, I attempted to produce a bricolage (Denzin \& Lincoln, 2000), a collage-like piece of art pieced together by multiple representations drawn from ethnography (critical) and biographic accounts of myself and those of my participants (teachers and learners).

Cobern (1995) describes the concept map "as an 'interpreted' overview of the ideas that appear to have the most importance for the participant and how various ideas are related" (p. 13). Accordingly, my narratives are also the interpreted overview that are grounded in auto-ethnography (self-culture dialectics, reflection of lived experiences), the methodology of my research. Firstly, I tried to see the writing as inquiry recollecting the nodal moments of my teachering profession, both from the profession and around the profession. Second, my concern in this research was the generation of data texts that included my own and my students' rigorous reflections during the process of journaling. Third, the interpretation of available data from personal practical perspectives had been implied. Next, I approached for interactive mode with the recent theories that tend to revolve around auto/ethnographic-reflective mode of research in writing. With all these activities in hand and in mind, I have drawn my final vision that might deal with my research question - How does journal writing help my students attain creativity, self confidence, cross cultural understanding, and transformation?

\section{Research Participants}

I reflected on the experience working with eighteen participants on the following basis:

- This study was conducted among 18 (eighteen) students of Mount Kailash University.

- The study is based on and guided by the researcher's auto ethnographic reflection.

This study was limited within the premises of Mount Kailash University's central campus, Dhunchey. Students were monitored during prewriting, on the spot writing, and post-writing about their attitude to journaling with reflective writing based on their classroom, reading, writing, presentation, and narrative associations. The study also incorporated Group Discussions among the students. The research has also included the researcher's (my) analysis on what students felt after journaling. The analysis was based on the concepts I mentally framed to see changes on them. I spent quality time with the research participants, immersed in their cultural contexts, in order to gain their confidence and encouraged them to disclose their cultural beliefs through reflective writing. 
I considered these 18 students pursuing second semester of ENGT 102, a communication skills course at the Undergraduate level, as my participants along with "me", another self that I tried to reflect. There are other three fictitious participants who contributed in this research by playing the role models of different types of teachers, namely Dr. Bishnu Sharma as a transmission teacher, Miss Rukmini Chaudhary as a constructivist teacher, and me, Mt. Motivation, as a transformative teacher. I chose a homogenous group as purposive sampling because the generation of specific and authentic data was possible only relying on them. In this research, the researcher has actively participated as a teacher facilitating the process of reflective writing.

\section{The Journey Adjoined for a Cross-cultural Understanding}

In many ways, the present day world promises well for expanding multidisciplinary and multicultural approaches in seeing everything, certainly without the exception of the process of teaching- learning. I acknowledged diversity for the contributions made by modern sociology, and sociologists as people have become more aware of the need for accounting for the particular systems of knowing different myths, cultures, fashion, and life styles not belonging only to the "self" but also to "others". Reflective writing also brings out the secrets of what people call from "others" and knowing and on this basis respecting multiplicity becomes instrumental in this sense.

"Writing stories are not about people and cultures 'out there' - ethnographic subjects (or objects). Rather, they are about ourselves - our work places, disciplines, friends, and family" (Richardson, 2005, p. 966). The practice of writing can also be justified on the ground that the cultural backgrounds of the literary work would broaden the views of students on other cultures by stirring up reflection, inducing feeling, and stimulating action. This process helps learners in gaining not only communicative but also creative competence. To cite Spry (2001) here, "Performing auto-ethnography has been a vehicle of emancipation from cultural and familial identity scripts that have structured my identity personally and professionally" (p. 708). Writing on what we have already held within us through an auto-ethnographic mode becomes a gateway in multicultural settings with all our hidden, suppressed pains and pleasures.

\section{Mammoth Understanding Level}

"Our culture conspires against collaborative thinking and the development of social competence by conditioning us to think adversarially in terms of winning or losing, of proving ourselves smart, worthy, or wise" (Mezirow, 2010, p.11). So, I think mammoth understanding is necessary to take us to a great power of knowing one another. Our stories tell us about our shared humanity, may it come from different cultures and religions, and/or in many guises and tongues. They have a lot to tell about new places, peoples, cultures, and customs. Silko (2002) writes, "You don't have anything if you don't have the stories" (p. 2). This line has always inspired me to justify the celebration of individual stories that could have been documented to gain energy in sharing oneanother's cross-cultural treasures, as Carr (2008) claims, "the plurality of students is necessary" (p. 82). Through journaling, and in its processes like free writing and peer-review, I do see the potential to promote critical self-reflection where dilemmas, 
contradictions, and evolving worldviews are questioned, challenged, and assimilated.

It is a valued result that I usually facilitate as a teacher when I attempt to support any inter-cultural activities among learners. Barone (2007) shares, "Narrative constructions with the power to lift the veil of conventionality from my eyes as they subtly raise disturbing questions about the necessity and desirability of comfortable, familiar educational discourses and practices" (p. 465). For my participants, learning something that is new or different, and then reflecting on what that means for a current or expected professional position can also be an interesting outcome at this stage.

Reflective writing on cultural themes or even focused on certain age group and gender can even be used as a way of understanding or gaining knowledge on a particular topic. Carr (2008) writes:

Affirming that something can be done, but that there is no prescriptive list that will quickly answer how to deal with such far-reaching issues as those discussed in this paper is a necessary precursor to transforming education, but this can only be obtained if teachers engage in critically examining themselves. (p. 94)

This typically involves asking students to draw on their own lives and experiences, as well as the lives of others with whom they are associated, to develop a critical self-reflection on some aspects of their personal development. For example, a student might obtain better understanding of adult development by keeping a journal that focuses on the various stages of personal development in her or his life. Schwandt (2007) shares:

While difficult to characterize in terms of a single set of features, critical ethnographies in the main are marked by several shared dispositions: a disavowal of the model of ethnographer as detached, neutral participant observer; a focus on specific practices and institutions more so than holistic portraits of an entire culture; an emancipator versus a solely descriptive intent; and a self-referential form of reflexivity that aims to criticize the ethnographer's own production of an account. (p. 2)

Not only do ethnographies, memoirs, and life stories encourage self-reflection, they also can promote a sharing of experiences with others to examine similarities and differences between and among individual life histories. I argue that journaling thus moves beyond learning as a solitary experience to one based on the potential of in-depth interaction with self and others.

Journaling contributes in exploring greater understanding among and between the practitioners and the culture they are (un)familiar with. "One of the reasons I wanted to become a professional educator, came from the feeling that there was something wrong with the ways I was taught at school and university" (Schwandt, 2007, p. 9). In this research, applying reflective practice of journaling for a semester, I along with my eighteen participants came up with some lived experiences.

Reflecting on my own journey of journaling, I also used to read any stories, poems, essays, and other texts without knowing the purpose, thus not finding the link with real life which therefore would not give pleasure in reading. But, in the course of time, I do read, interpret, think critically, and assimilate any texts and the contexts as well. 
When I write after reading novels and stories, watching movies, even after visiting some new historical/natural/cultural places and observing such practices, I find myself more tolerant of these subjects with greater level of respect. A participant assimilates the practice of journaling with what his grandfather told her or him:

\begin{tabular}{ll}
\hline $\begin{array}{l}\text { My grandfather said, "A good } \\
\text { teacher teaches his students fishing } \\
\text { instead of giving them fish to eat". I }\end{array}$ & $\begin{array}{l}\text { Instead of getting the fish, s/he is gratified for } \\
\text { acquiring the art of fishing. This disclosure } \\
\text { cound that in this course. }\end{array}$ \\
$\begin{array}{l}\text { way so that students can inherit the holistic kind } \\
\text { of approaches in life, not to learn anything in } \\
\text { isolation. }\end{array}$ \\
\hline
\end{tabular}

I take sense as a feeling about something attractive, may it be very important or trivial sometimes, involving one's personal understanding or judgment in something and sensibility as an ability to experience and understand deep feelings, and for me most of the times in the form of art and literature.

While reflecting on this practice of journaling, I also recall the moment that had bizarre consequences. Once I asked my students to write about their family thinking that could be a means to purgation which had a fine link with the text we discussed that day, The Cabuliwallah, a story by Rabindranath Tagore. While revealing such in the classroom would be disastrous as I could see the possibility that students might start to become so emotional and even would burst into tears sometimes as they/we would unfold our stories. "The use of story has become quite popular in educational circles and is increasingly being recognized as a vehicle for professional development" (Elliott \& Drake, 1999, p. 1). I recall it when I discussed The Cabuliwallah and asked students to reflect on the best moment they enjoyed with their parents. It so happened unexpectedly that one of the female students fell down, making the whole setting very unpleasant. In spite of my good interest to produce the similar text, the intention to create a good reflective writing dealing with family affection, the class came to a stand-still and could not proceed further. For which, I had to ask for forgiveness from the student before I advanced for the next class as she had lost her father the previous month and that was not the appropriate activity I should have done in the class that moment.

Another incident also helped me regard different cultural backgrounds and the principles they were developed during my teachering career. In my earlier days of university teaching, I unknowingly tried to enforce discipline codes among students which were very common as a high school teacher, but not a welcoming one in colleges.

I remember I was very authoritarian to one of the back benchers for not bringing the book and also not reading the text in advance. During my long years of school teaching, that used to work very well. But, the same practice resulted in the other way at Mount Kailash University. Those late teen aged group of young students did not at all appreciate my "rude" discipline enforcement to their peer. They rather chose to protest by asking together if they had to read what the use of the teacher was, then. "Is it not the teacher who is supposed to make us all understand no matter whether we read or not?" they retorted in a united voice. 
As soon as I entered the Undergraduate class room that day, I stepped into the course introduction followed by a set of dos' and don'ts that made all realize with the same music which had also haunted them in the past. Yes, I also discussed some approaches to excel in their reading and writing pace. At the end, I still remember, I strictly reminded them to read the text before joining the following week's class.

Scene One: An Authoritarian or an Authoritative Teacher!

Here, I have prepared an anecdote as an example of how an authoritarian teacher likes to control every move the students make while they struggle hard in bargaining boundaries to explore the courage from within their own natural authority, even by saying "no" as a remedial reserve.

\section{Who is the Self that Teaches?}

(As we met for our class the following week, I tried to check whether they came after reading the textbook.)

Teacher: Did you all read the text we are going to discuss today?

Students (More than half of that class of 30 students replied): "No-s'arr".

"Wow!" was my response.

(With a fine smell of anger, I asked them whether they possessed the text book. There came an "obvious" answer, "Nowt yet bought, s'ar" from the majority, and I then realized why they had not read the text that was to be discussed in the class that day.

This way, right before the degree of my anger was about to exceed from the highest possible limit, I announced that those who had not bought and/or brought the book could leave the class.

There appeared a fine "what to do" moment when one student boldly started to interrupt.)

Student 3: Excuse me, S'arr...

Teacher: Hello, yes! Go ahead, what's the matter?

Student 3: I have a question to you.

Teacher: Yes, what is it?

Student 3: Actually, it is not only a question but more...., a suggestion, may be.

Teacher: Yes, yes... let me take it, then.

Student 3: Sir, when we read ourselves, what is the use of a teacher? So, why can't you just teach when your job is so simple, just to teach?

Teacher: Oh, yes. But, I more believe in making the learning possible rather than "one way" traffic, the teaching. Therefore, if you had also read, you could perform even better so well that even while asking questions to me, or to any other teachers, you could feel comfortable.

Student 3: I know Sir. But I still expect everything from the teacher.

Recalling the misunderstanding, I composed a poem (Haiku) the same night capturing the student-teacher relation using the metaphors as Deacon (2006) shares, "Research participants can use metaphors to describe their experiences, feelings, or specific events" (p. 101). When language develops different meaning as words become 
more vivid, we capture moods and interpretations in metaphors. To describe one thing using an analogy of another, I felt comfortable using metaphors not to harm the self and also that the participants had more freedom to use their creativity and own experiences to reflect on the specific topic. They were encouraged to leave their established mental sets to think of the topic in a new and varied way.

I now realize that my attitude in pleading students to stick to the books or read them before coming to the class would have worked better if I associated it in theorizing reflective practice. What I did then was just asked the boy only to read and carry the book where he did not find the link with its purpose. But as a reflective teacher, I was the one "who constantly (would) question his or her own aims and actions, monitors practice and outcomes, and considers the short term and long-term effects" (Pollard $\&$ Tann, 1987, p. 5) upon each student. Therefore, I now agree on the cause of that unpleasant event that even led to the protest giving space to some people to doubt on my validity of being an ideal teacher. Such disasters may have been eluded if I asked them to reflect on what we did on the previous day or if I started the class by asking them to think of any of the themes that I was going to discuss that day working among and within themselves with the help from their text books and their own lived experiences. "Teachers should be cognizant of how their teaching can shape the context for students as well as how their ability to accept that their own learning is never complete and, equally, is a factor in establishing the parameters for critical engagement" (Noel, 2000; Nieto \& Bode, 2008, as cited in Carr, 2008). This way, I also realized that perfection was only a journey, never being the destination.

If there is no hope for education to lead to transformational change in individuals, in communities, in societies, and at the international level, then the neo-liberal focus on employability and competition will translate into the simple reproduction of social relation. (Bourdieu \& Passeron, 1977; Hill, 2003, as cited in Carr, 2008)

I also wanted to get adapted myself "through much of the sociological literature which aims to empower students and teachers" (Banks, 2008; Delpit, 1988; Nieto, 1999, p. 92, as cited in Carr, 2008).

While analyzing these excerpts, I did recall my own anecdotes written as a teacher that helped me transform as an appreciative evaluator (learner-centered) too in giving rightful judgment to students' collective work. Sometimes, when I focused on a learner-centered approach, students would find me extremely deviated from the exam centered traditional mode of teaching.

Impasse
Student and teacher
The two wheels of a chariot
But, never moving.

\section{Quantity or Quality?}

Quantity refers to an amount or number of something, primarily the measurement by seeing how much of it there is where as quality refers to the standard of something when it is compared to other things like it; how good or bad something is. Mount Kailash University, as claimed in its mission statement that its primary aim is to prepare quality leadership, is more inclined to quality than quantity. And as a dedicated 
faculty, I am also prepared for it. Thinking "the democratic impulse of narratives to rectify historical wrongs through a widening of the discursive space is easily understood" (Barone, 2007, p. 463), here are two more vignettes; one with a brilliant student and the other with Dr. Inspection.

\section{Scene Two: An Unfortunate Encounter}

(As an innocent face enters my room, while working with other students' assignments, I was talking with my colleagues too.)

Student: Good morning, sir.

Teacher (Myself): Hi, dear. Good morning.

Student: Sir, I have a serious problem.

Teacher (Myself): Yes, yes. Tell me.

Student: (sobbing, very unhappy)

Teacher (Myself): Oh, dear - - - Tell me, what's the matter?

Student: Sir, I got the mark-sheet today, and do you think I only deserve a "C" in English?

Teacher (Myself): (Shocked, really knocked, and disappointed) You do deserve more than that, a "B" at least.

Student: (Very aggressive) Then why was I thrown with a "C"? What should I do now?

Teacher (Myself): (I had no answer, very stunned) Man! I must be sorry for what has happened, but there are various factors contributing for the cause. All I can suggest you now is to go for the re-totaling or re-checking of your final papers.

Student: No problem sir, I do not worry a little. This is only to let you know how I became the prey, and to help you to make sure there will be no-one to be victimized in future and that is also just because of your "so-called" studentcentered approach and the university's set-standard.

Teacher (Myself): Thank you. And I will also take the matter seriously. ***Leave -- all students $* * *$

I could not sleep for several nights after that encounter. I put myself in this position having crossed the borders. That wrenched me deeply. Then, I pondered what I could do.

However, I was so embarrassed that day, and I even wanted to go and talk to Dr. Inspection, but could not dare to as it was not considered a decent conduct to manipulate the Examination process. I was in dilemma, "to do or not to do, to be or not to be, to continue the "so called" approach or not to as in Shakespeare's Hamlet, this haunted me all the time, the ghost of my own earlier deeds, the risk that I took claiming for better, the student centered journaling approach.

But, the following day I got a call from the Examination section (Department). Some other students too had already gone to their respective department heads and through the heads, for those students' poor results Dr. Inspection was consulted. I proceeded towards the office of Dr. Inspection - finally. 


\section{Scene Three: My Encounter with Dr. Inspection}

Dr. Inspection: Yes, there is a complaint about you that none of the students from the group you taught scored an A. Also, two students failed in the final exam. Why is that?

Mt. Motivation: (God! The same happened that I sensed earlier.) Well, if you are willing to regard my sincere efforts to transform the students, and keep the patience to listen to me, my students have neither performed less nor they failed their exams. They are the students who must have performed very well, or even excelled every other student. It was all because of the "red gap" between my participatory approaches in making the students learn through their own efforts and that of our traditional exam system which did not tally with their performance. Believe me, the students are superb! I am even doing a research on the effectiveness of learning based on their performance.

Dr. Inspection: So, you mean you are reliable even your students are suffering and rather love to blame our system, right?

Mt. Motivation: But, I define it differently, sir, expecting that you also accept the multiple truths. I still see problem in our exam oriented teaching system where teachers distribute model questions and give the exams accordingly. When I stand at the different pole advocating the value of learning for life, students seem worrying for the marks; some even need counseling on the "fruit of real learning".

Dr. Inspection: Then, why don't you teach them according to their needs?

Mt. Motivation: The problem is not in teaching sir. How can we still judge the students on the same traditional exam centered approach when the whole academia is inclined to the multiplicity? How can we say a particular student lacked a lot just because s/he could not satisfy the "single" perspective of an examiner? And, can't we ask student to write on what they comfortably know than just making the whole process of learning complicated that leads students to the level of frustration, and even to failure?

Dr. Inspection: So, can you give your suggestion in writing so that I can discuss the matter in a meeting.

Mt. Motivation: My pleasure sir! (But, this made me much worried... why my students, though most of them really enjoyed learning, performed so well and still could not excel in the final exam.)

Because of the traditional settings, students would sometimes doubt on my authenticity, even worrying a lot about the final results as my approach of teaching was really different from what they were used to - the rote learning or the total lecture methods. As Travis (2001) shares:

Critical research is not for everyone in that it can arguably only be done effectively if you feel a sense of injustice about the way particular groups are 
treated in society, in which case it is likely that you may already be involved in a pressure group. (p. 23)

This way, my approach would seem completely different from other classes where some of my colleagues gave non-stop lectures with some tips for exam. I agree with Luitel (2009) who admits:

In rereading the story, I revisited my role as a teacher educator and asked some critical questions of myself. Was my role adequate for improving the situation? How did I help the teacher to be more inclusive and dialogical in conducting his activities? To what extent did teachers benefit from my ways of supporting them? I tried to reveal my weaknesses in my situated-ness, as well as my strengths. (p. 225)

But I shared my ideas with colleagues in one of the Department's regular Presentation series, too. I would also reflect time and again on the legitimacy of my advice, whenever my colleagues found difficult to agree with me.

I called a meeting to discuss the agenda with my colleagues. In that meeting, there were also some other issues; teachers were very strict with the deadlines, authenticity, and originality of ideas, and so on. The practice of journaling had invited some unpleasant moments when the teachers caught some students for plagiaristic offences. However, when we started to believe in their (students') diverse possible musings, a gradual process of reflective journaling, they would all produce their writing day by day, not with pressure but with ample pleasure, we (teachers and students) headed to better understanding. In his journey of journaling, one student commented that the space he had in that voluminous "number 3" register was not enough for him, as writing became his passion every next moment.

\section{Conclusion}

As a researcher and teacher, I learned that my contact with participants' narratives, colleagues' experiences and an encounter with Dr. Inspection had been rather limited in the beginning. When I reflected on all those at the end of their course, there began the coming of the great diversity of voices different from the ones heard earlier. The multiplicity of voices in which they wrote made me increasingly aware of the importance of sharing in the group. Being both, the teacher and the researcher, my interactions with these participants, the undergraduate students with their own narratives in the university setting, proved to be a special experience in cross-cultural understanding where the practice of journaling has become a transformative experience as even the terrible creatures could transform from caterpillars to blithe butterflies. When exposed to a platform of voices, the culture as a whole has become a shared treasure crossing our petty "self(ish)" borders.

\section{Note}

1 Pseudonym for one of the higher education institutions in Nepal, and the site of present research where the researcher "I" is also the facilitator of the data-text. 


\section{References}

Barone, T. (2007). A return to the gold standard? Questioning the future of narrative construction as educational research. Qualitative Inquiry, 13(4), 454-470.

Berger, L. (2001). Inside out: Narrative autoethnography as a path toward rapport. Qualitative Inquiry, 7(4), 504-518.

Bolton, G. (2001). Reflective practice. London: Paul Chapman.

Carr, P. R. (2008). "But what can I do?" Fifteen things education students can do to transform themselves in/through/with education. International Journal of Critical Pedagogy, 1(2), 81-97.

Cobern, W. W. (1995). Worldview-reality as viewed by students: A synoppsismethodology. Paper presented at the annual meeting of National Association for Research in Science Teaching, San Fransisco, CA.

Colonna, M. R., \& Gilbert, J. E. (2006). Reason to write. London: Oxford.

Creswell, J. W. (2002). Research design (2nd ed.). California: Sage.

Deacon, S. A. (2006). New ideas for old methods: Creativity within qualitative research on families. Retrieved from http://www.sagepub.com/upm-data/10992_ Chapter_5.pdf

Denzin, N. K., \& Lincoln, Y. S. (2000). Introduction: The discipline and practice of qualitative research. In N. K. Denzin \& Y. S. Lincoln (Eds.), Handbook of qualitative research (2nd ed., pp.1-28). Thousand Oaks, London: Sage.

Denzin, N. K., \& Lincoln, Y. S. (Eds.). (2005). The Sage handbook of qualitative research (3rd ed.). London: Sage.

Elbaz-Luwisch, F. (2002).Writing as inquiry: Storying the teaching self in writing workshops. OISEUT, 32(4), 403-428.

Elliott, A., \& Drake, S. M. (1999, April). Concentric storying: A vehicle for professional development in teacher education. Paper presented at AERA, Montreal PQ.

Ellis, C., \& Bochner, A. P. (2000). Autoethnography, personal narrative, reflexivity: Researcher as subject. In N. K. Denzin \& Y. S. Lincoln (Eds.), Handbook of qualitative research (2nd ed., pp. 733-768). Thousand Oaks, CA: Sage.

Guba, E. G., \& Lincoln, Y. S. (2005). Paradigmatic controversies, contradictions and emerging confluences. In N. K. Denzin \& Y. S. Lincoln (Eds.), The Sage handbook of qualitative research (3rd ed., pp.191-216). Thousand Oaks, CA: Sage.

Hart, T. (2004). Opening the contemplative mind in the classroom. Journal of Transformative Education, 2(1), 28-46.

Hitchcock, G., \& Hughes, D. (1989). Research and the teacher. London: Routledge. Hiemstra, R. (2001). Uses and benefits of journal writing. In L. M. English \& M. A. Gillen (Eds.), Promoting journal writing in adult education (New Directions for Adult and Continuing Education, No. 90, pp. 19-26). San Francisco: JosseyBass. 
Luitel, B. C. (2009). Culture, worldview and transformative philosophy of Mathematics education in Nepal: A cultural-philosophical inquiry (Unpublished doctoral dissertation). Curtin University of Technology, Australia.

Luitel, B. C. (2009). Storying, critical reflexivity, and imagination: A transformative approach to contextualized professional development research as/for culturally contextualized professional development. In P. C. Taylor \& J. Wallace (Eds.), Contemporary qualitative research: Exemplars for science and mathematics educators (pp. 217-228). Dordrecht, The Netherlands: Springer.

Luitel, B. C., Belbase, S., \& Taylor, P. C. (2008). Autoethnography: A method of research and teaching for transformative education. Journal of Education and Research, 1(1), 86-95.

Mezirow, J. (2010). Transformative learning: Theory to practice. Retrieved from http:// www.ecolas.eu/content/images/Mezirow\%20Transformative\%20Learning.pdf

Mirchandani, R. (2005). Postmodernism and sociology: From the epistemological to the empirical. Sociological Theory, 23(1), 86-115.

Moon, J. (1999). Learning journals: A handbook for academics, students and professional development. London: Kogan Page.

Patton, M. Q. (2001). Qualitative evaluation and research methods (3rd ed.). Thousand Oaks, CA: Sage.

Pereira, L. (2007). Developing perspectival understanding. In P. C. Taylor \& J. Wallace (Eds.), Contemporary qualitative research: Exemplars for science and mathematics educators (pp. 189-203). Dordrecht, The Netherlands: Springer.

Pollard, A., \& Tann, S. (1987). Reflective teaching in the primary school: A handbook for the classroom. Cambridge, UK: Cassell Education.

Reed-Danahay, D. (1997). Auto/ethnography. New York: Berg.

Schwandt, T. A. (2007). Critical ethnography: The SAGE dictionary of qualitative inquiry. Delhi: Sage.

Silko, L. M. (2002). Ceremony. New Delhi: Penguin Books.

Spry, T. (2001). Performing autoethnography: An embodied methodological praxis. Qualitative Inquiry, 7(6), 706-732.

Strauss, A., \& Corbin, J. (1990). Basics of qualitative research: Grounded theory procedures and techniques. Newbury Park, CA: Sage Publications, Inc.

Taylor, P. C., Settelmaier, E., \& Luitel, B. C. (2012). Multi-Paradigmatic transformative research as/for teacher education: An integral perspective. In K. Tobin, B. Fraser, \& C. McRobbie (Eds.), Second international handbook of science education (pp. 373-388). Dordrecht, The Netherlands: Springer.

Travis, M. (2001). From description to critique. Qualitative research through case studies. Retrieved from http://www.sagepub.com/upm-data

Whitehead, J. (2000, April). 'How do I improve my practice?' Creating a discipline of education through educational enquiry. Paper presented at the 7th International Conference on Teacher Research at Baton Rouge. 